\section{A Randomized Comparative Study of Two Techniques to Optimize the Root Coverage Using a Porcine Collagen Matrix}

Danilo Maeda Reino, Luciana Prado Maia, Patrícia Garani Fernandes, Sergio Luiz Scombatti de Souza, Mario Taba Junior, Daniela Bazan Palioto, Marcio Fermandes de Moraes Grisi, Arthur Belém Novaes Jr.
Department of Surgery, Oral and Maxillofacial Traumatology and Periodontology, School of Dentistry of Ribeirão Preto, USP - Universidade de São Paulo, Ribeirão Preto, SP, Brazil

Correspondence: Arthur Belém Novaes Jr, Avenida do Café, s/n, Monte Alegre, 14040-904 Ribeirão Preto, SP, Brasil. Tel: +55-16-3602-3980. e-mail: novaesjr@forp.usp.br

\begin{abstract}
The aim of this randomized controlled clinical study was to compare the extended flap technique (EFT) with the coronally advanced flap technique (CAF) using a porcine collagen matrix (PCM) for root coverage. Twenty patients with two bilateral gingival recessions, Miller class I or II on non-molar teeth were treated with $\mathrm{CAF}+\mathrm{PCM}$ (control group) or $\mathrm{EFT}+\mathrm{PCM}$ (test group). Clinical measurements of probing pocket depth (PPD), clinical attachment level (CAL), recession height $(\mathrm{RH})$, keratinized tissue height $(\mathrm{KTH})$, keratinized mucosa thickness (KMT) were determined at baseline, 3 and 6 months post-surgery. At 6 months, the mean root coverage for test group was $81.89 \%$, and for control group it was $62.80 \%(p<0.01)$. The change of recession depth from baseline was statistically significant between test and control groups, with an mean of $2.21 \mathrm{~mm}$ gained at the control sites and $2.84 \mathrm{~mm}$ gained at the test sites $(p=0.02)$. There were no statistically significant differences for KTH, PPD or CAL comparing the two therapies. The extended flap technique presented better root coverage than the coronally advanced flap technique when PCM was used.
\end{abstract}

Key Words: gingival recession, periodontal plastic surgery, tissue graft.

\section{Introduction}

The treatments of gingival recessions remain a challenge for clinicians and patients, due to their variable success rates $(1,2)$. Several treatments have been proposed and many surgical techniques have been developed (1) but, until today there is no consensus on the clinical protocol for the treatment of gingival recession (1). The predictability of results varies according to the employed surgical technique (1). Systematic reviews have shown better results for root coverage by the addition of gingival grafts $(1,2)$. The subepithelial connective tissue grafts (SCTG) are able to increase the rate of root coverage, gingival thickness and predictability of the results (1).

Although clinicians prefer using SCTG to optimize clinical outcomes, it may not be accepted by many patients (3). This lack of acceptance is consequence of the need for a second surgical site to harvest the gingival graft, which increases the surgical chair time, morbidity and discomfort (3). SCTG has technical limitations, like limited tissue source and risk of injury to vital structures like nerves and blood vessels (3).

Currently there are biomaterials designed to replace for gingival grafts, aiming to reduce morbidity, surgical risks, clinical time and increase patient compliance. The xenogeneic porcine collagen matrix (PCM) is a new biomaterial which has two distinct layers, allowing regeneration of gingival tissues (4). The PCM was developed to be an alternative to free gingival grafts (3) and has recently been used for root coverage $(5,6)$.
Comparing the SCTG with PCM for root coverage, the results obtained for PCM were considered inferior (6). In a previous study, the same surgical technique (coronally advanced flap) (7) was used to cover both PCM and SCTG. This technique has vertical releasing incisions that are positioned close to the grafts, decreasing the vascularity, which can jeopardize the root coverage results. The PCM has no blood vessels and cannot be exposed in root coverage procedures; in this way, the surgical technique should be adapted to compensate the limitations of the PCM and guarantee results comparable to SCTG. Thus, the extended flap technique (8), which increases the graft's vascularity, reduces the chance of graft exposure and has previously shown superior results in terms of root coverage with the use of non-autogenous grafts (12), seems to be an interesting alternative to be evaluated in association with PCM $(5,6,9)$. Thus, the aim of this study was to compare EFT (8) with $\mathrm{CAF}$ (7), both combined with PCM for root coverage, with the hypothesis of better root coverage for EFT.

\section{Material and Methods}

\section{Patient Selection}

This study was a randomized controlled clinical trial using a split-mouth design to compare the outcomes of two different surgical procedures for gingival recession treatment. The test power calculation with a significance level of 5\% and $80 \%$ power, determined that 17 patients were needed to detect $1 \mathrm{~mm}$ difference in root coverage 
between both techniques. Due to possible dropouts, 20 patients were selected for the study at the Department of Periodontology, Dental School of Ribeirão Preto, USP - Universidade de São Paulo. The study was approved by the Human Research Committee of the Institution (2010.1.1217.58.7), was conducted according to the principles outlined in the Declaration of Helsinki on experimentation involving human subjects and received the identifier NCT02129504 at Clinicaltrials.gov. The ages of the patients selected for this study were between 26 to 46 years old. Patients were enrolled between March 2011 and October 2011. Patients with bilateral gingival recession, Miller class I or II (10), at least $3 \mathrm{~mm}$ high, less than $3 \mathrm{~mm}$ of keratinized tissue and cementoenamel junction (CEJ) visible in non-molar teeth were chosen. Exclusion criteria were: diabetes, pregnancy, chronic use of medication, periodontitis or any condition that could contraindicate the surgery. All patients agreed with the study protocol and signed a consent form prior to treatment.

\section{Pre-Surgical Clinical Procedures}

After complete periodontal examination, the patients received general oral hygiene instructions to eliminate

\section{Data Collection}

Two teeth in the same arch, bilaterally, were included in the study. The following clinical measurements were taken before the surgical treatment (baseline), 3 and 6 months after surgery at the mid-buccal point of the involved tooth: a) probing pocket depth, b) clinical attachment level, c) gingival recession height, d) gingival recession width, f) amount of keratinized tissue, g) width of the papillae adjacent to the recession, $h$ ) height of the papillae adjacent to the recession and i) gingival thickness $1 \mathrm{~mm}$ above and under the mucogengival junction. Blinded clinical examinations were always carried out by the same operator (P.G.F.), who was previously calibrated (intra-examiner calibration). A computerized force-controlled periodontal probe was used for probing depth, clinical attachment level and bleeding on probing. A digital caliper was used to measure the other clinical parameters at the mid-buccal point of the selected tooth.

\section{Surgical Procedures}

The side to receive each type of treatment was selected by randomization performed by a single examiner (L.P.M.) using a software (Microsoft Excel version 14, Redmond,
WA, USA) by a computer-generated randomly permuted block. Allocation was concealed with envelopes until immediately before surgery to determine which side would receive the control or test technique. The control group received CAF technique (7) + PCM (Mucograft collagen matrix; Geistlich Pharma, Wolhusen, Switzerland), while the test group received the extended flap technique (8) + PCM. Both surgical procedures were performed in the same session by the same surgeon (D.M.R.), who was not involved in the clinical measurements.

The CAF (7) consists of an intra-crevicular incision on the buccal surface of the tooth, releasing incisions on the mesial and distal side of the same tooth, avoiding the adjacent papillae. A split thickness flap was raised beyond the mucogingival junction and, after its base was released, the flap was passively advanced to crown to cover both the gingival recession and PCM.

The EF technique (8) uses an intra-crevicular incision on the buccal surface of the tooth which includes both adjacent teeth as well. Releasing incisions were performed mesially and distally of the two adjacent teeth, without including the adjacent papillae. A split thickness flap was raised beyond the mucogingival junction and, after its base was released, the flap was displaced coronally and passively to cover both the gingival recession and PCM graft.

Following flap deflection, both groups received scaling and root planning on the exposed areas using Gracey curettes number $5 / 6$, and the area was rinsed abundantly with a sterile saline solution. The PCM was trimmed using Goldman-Fox scissors to adapt over the gingival recession areas. The PCM was then sutured to the receptor site using nylon sling sutures. Then, the flap was coronally positioned to completely cover the area and also sutured with nylon sling sutures. Figures 1 and 2 presents the surgical sequences for the Control and Test Groups, respectively. All patients were instructed to discontinue tooth brushing. A 0.12\% chlorhexidine digluconate mouthrinse was prescribed twice a day for 15 days, and were then instructed to clean the operated area with cotton swabs embedded in the same solution. They also received analgesic prescription for 3 days; no antibiotics were prescribed. Thirty days later, the patients were allowed to carefully resume tooth brushing over the operated area.

The patients were recalled to be reinstructed on oral hygiene procedures and prophylactic control at 2 and 4 weeks post-surgery, and then monthly until 6 months post-surgery.

\section{Statistical Analysis}

Statistical analysis was defined after the result of normality test: it was comparative and non-parametric $(n=20)$. Mann-Whitney test was used to compare data between the groups in the pre-treatment, 3 months, 6 
months and postoperative periods. A two-way ANOVA test was used to compare the clinical parameters in relation to the surgical techniques and the time intervals (intra-group difference: Baseline $X 3$ months; Baseline $X$ 6 months). For all statistical analyses $p<0.05$ was chosen.

\section{Results}

Among the 20 patients that were part of the sample, 14 were women and 6 were men. The mean age was $42 \pm 7.42$ years (range: $26-46$ years). All cases were classified as Miller's Class I (10), and were found in 8 maxillary canines, 4 mandibular canines, 12 mandibular first pre-molars and 16 maxillary first pre-molars. All patients completed the follow-up and the clinical data are shown in Table 1. Table 2 shows the root coverage obtained in height and width according to each technique, and the gingival tissue gain

Table 1. Means and standard deviations of clinical parameters assessed at baseline, 3 and 6 months for test and control groups

\begin{tabular}{|c|c|c|c|c|c|c|c|}
\hline \multirow{2}{*}{ Clinical parameters } & \multirow{2}{*}{ Group } & \multirow{2}{*}{ Baseline (a) } & \multirow{2}{*}{3 months (b) } & \multirow{2}{*}{6 months (c) } & \multicolumn{3}{|c|}{$\mathrm{p}$ inter group } \\
\hline & & & & & $\mathrm{a} \times \mathrm{b}$ & $\mathrm{a} \times \mathrm{c}$ & $\mathrm{b} \times \mathrm{c}$ \\
\hline \multirow{3}{*}{ Probing depth } & Control & $1.82 \pm 0.48$ & $2.29 \pm 0.66$ & $2.18 \pm 0.39$ & ns & ns & ns \\
\hline & Test & $1.82 \pm 0.48$ & $2.24 \pm 0.66$ & $2.00 \pm 0.39$ & ns & ns & ns \\
\hline & $\mathrm{p}$ value & ns & ns & ns & & & \\
\hline \multirow{3}{*}{ Clinical attachment level } & Control & $5.31 \pm 0.89$ & $3.63 \pm 1.02$ & $3.46 \pm 1.12$ & $<0.05$ & $<0.01$ & ns \\
\hline & Test & $5.29 \pm 0.91$ & $2.88 \pm 1.30$ & $2.63 \pm 1.18$ & $<0.01$ & $<0.01$ & ns \\
\hline & $\mathrm{p}$ value & ns & ns & ns & & & \\
\hline \multirow{3}{*}{ Keratinized tissue width } & Control & $1.66 \pm 0.73$ & $1.95 \pm 0.73$ & $2.01 \pm 0.74$ & ns & ns & ns \\
\hline & Test & $1.74 \pm 0.76$ & $1.79 \pm 0.56$ & $1.71 \pm 0.65$ & ns & ns & ns \\
\hline & $\mathrm{p}$ value & ns & ns & ns & & & \\
\hline \multirow{3}{*}{$\begin{array}{l}\text { Gingival thickness } \\
1 \mathrm{~mm} \text { below CEJ }\end{array}$} & Control & $1.18 \pm 0.18$ & $1.71 \pm 0.54$ & $1.44 \pm 0.34$ & ns & ns & ns \\
\hline & Test & $1.24 \pm 0.18$ & $1.46 \pm 0.48$ & $1.29 \pm 0.34$ & ns & ns & ns \\
\hline & $p$ value & ns & ns & ns & & & \\
\hline \multirow{3}{*}{$\begin{array}{l}\text { Gingival thickness } 1 \\
\text { mm above CEJ }\end{array}$} & Control & $1.19 \pm 0.18$ & $1.54 \pm 0.43$ & $1.36 \pm 0.35$ & ns & ns & ns \\
\hline & Test & $1.11 \pm 0.20$ & $1.37 \pm 0.46$ & $1.24 \pm 0.36$ & ns & ns & ns \\
\hline & & ns & ns & ns & & & \\
\hline \multirow{3}{*}{ Base of mesial papilla } & Control & $2.59 \pm 0.57$ & $2.61 \pm 0.54$ & $2.50 \pm 0.49$ & ns & ns & ns \\
\hline & Test & $2.57 \pm 0.42$ & $2.29 \pm 0.51$ & $2.22 \pm 0.43$ & ns & ns & ns \\
\hline & $p$ value & ns & ns & ns & & & \\
\hline \multirow{3}{*}{ Mesial papilla height } & Control & $2.99 \pm 0.40$ & $2.93 \pm 0.53$ & $2.91 \pm 0.48$ & ns & ns & ns \\
\hline & Test & $3.16 \pm 0.53$ & $3.00 \pm 0.46$ & $2.92 \pm 0.48$ & ns & ns & ns \\
\hline & $p$ value & ns & ns & ns & & & \\
\hline \multirow{3}{*}{ Base of distal papilla } & Control & $2.32 \pm 0.45$ & $2.37 \pm 0.39$ & $2.26 \pm 0.37$ & ns & ns & ns \\
\hline & Test & $2.37 \pm 0.39$ & $2.10 \pm 0.37$ & $1.98 \pm 0.33$ & ns & ns & ns \\
\hline & $p$ value & ns & ns & ns & & & \\
\hline \multirow{3}{*}{ Distal papilla height } & Control & $2.88 \pm 0.51$ & $2.89 \pm 0.66$ & $2.73 \pm 0.59$ & ns & ns & ns \\
\hline & Test & $2.76 \pm 0.57$ & $2.76 \pm 0.60$ & $2.85 \pm 0.52$ & ns & ns & ns \\
\hline & $p$ value & ns & ns & ns & & & \\
\hline
\end{tabular}

Comparison between groups and inter groups for several times by ANOVA, $p>0.05$. ns $=$ not significant. 
and root coverage percentage according to the initial size of gingival recession.

Wound healing was uneventful in all cases, with no graft exposure. There was no change in the height or width of the mesial or distal papillae during the evaluation period. There were no statistical differences in gingival thickness. The keratinized tissue height did not change, as well as the probing depth, which remained unchanged. The clinical attachment level in both test and control groups showed clinical attachment gain, as compared with baseline.

Both techniques showed a decrease in gingival recession with a statistically significant difference, the test group showed greater root coverage in height and in width compared to the control group.

\section{Discussion}

Many surgical techniques have been described for the treatment of gingival recessions, but systematic reviews came to the conclusion that the CAF technique associated with SCTG $(1,2)$ is the gold standard treatment due to its greater predictability when compared with other techniques (11). The CAF + PCM technique has shown inferior results when compared to SCTG. In 2010, McGuire and Sheyer $\vec{s}$ (6) compared CAF + SCTG with CAF + PCM and obtained $88.5 \%$ (test group) against $99.3 \%$ (control group) of root coverage $(p=0.0313)$, respectively, after 12 months. Using

Table 2. Results (\%) of the surgical techniques for recession height, recession width and root coverage, after 3 and 6 months

\begin{tabular}{lccc}
\hline & Control & Test & $\mathrm{p}$ \\
\hline Recession height & & & \\
Baseline & $3.49 \pm 0.61$ & $3.47 \pm 0.60$ & 0.3969 \\
3 months & $1.34 \pm 0.60$ & $0.64 \pm 0.60$ & 0.0042 \\
6 months & $1.28 \pm 0.54$ & $0.63 \pm 0.44$ & 0.0149 \\
Change from baseline to $3 \mathrm{~m}$ & $-2.15 \pm 0.65$ & $-2.83 \pm 0.68$ & 0.0056 \\
Change from baseline to $6 \mathrm{~m}$ & $-2.21 \pm 0.60$ & $-2.84 \pm 0.68$ & 0.0261
\end{tabular}

Recession width

\begin{tabular}{lccc} 
Baseline & $3.58 \pm 0.52$ & $3.68 \pm 0.55$ & 0.2462 \\
3 months & $2.61 \pm 1.16$ & $2.05 \pm 1.69$ & 0.1331 \\
6 months & $2.65 \pm 1.08$ & $2.46 \pm 1.22$ & 0.0813 \\
Change from baseline to $3 \mathrm{~m}$ & $-0.94 \pm 0.85$ & $-1.57 \pm 1.39$ & 0.06 \\
Change from baseline to $6 \mathrm{~m}$ & $-0.90 \pm .0 .94$ & $-1.18 \pm 0.94$ & 0.03 \\
& & & \\
Root coverage & & & \\
3 months & $60.78 \pm 14.95$ & $82.33 \pm 16.64$ & $<0.01$ \\
6 months & $62.80 \pm 13.13$ & $81.89 \pm 12.85$ & $<0.01$ \\
\hline
\end{tabular}

$p$ values obtained by Mann Whitney test, comparison between groups at the same time of evaluation. the same technique, other studies reported $94.32 \%$ of root coverage for the test group (PCM) and $96.97 \%$ for the control group (SCTG) after 12 months, without statistical difference between the groups (9). A multicenter study (5) treated 90 gingival recessions in 45 patients using the same technique (CAF), one side with PCM and the other without PCM. After 6 months the root coverage obtained for the test group was $75.29 \%$ against $72.66 \%$ for the control group, without significant differences between the groups ( $p=0.169)$.

The number of clinical studies reporting the use of porcine matrix for root coverage of single recessions is still small, and all of them used CAF as the surgical technique. The results of PCM have been lower or with no statistical differences compared with SCTG $(5,6,9)$. Although the PCM was developed as a substitute for SCTG, a multicenter study demonstrated that PCM use has not provided better results than CAF alone (5). On the other hand, the studies comparing PCM with SCTG consistently showed better results $(1,2)$ with the use of the autologous graft.

SCTG is an autologous tissue with live cells, blood vessels and other constituents such as collagen. PCM is formed solely by collagen, and therefore the healing and incorporation processes are different from SCTG. These differences may account for the lower results in root coverage when PCM and SCTG are compared using the same surgical techniques. Standard surgical techniques were created for SCTG and may not provide the same results when SCTG is replaced by a biomaterial. Therefore, the extended flap technique (8) was developed in an attempt to improve the results using biomaterials as grafts. Comparing EFT and CAF using acellular dermal matrix (8), the root coverage was superior in the EFT group after 6 months. The authors concluded that these results are due to the placement of the releasing incisions away from the area to be covered, which prevented exposure of the biomaterial and more important, enable better vascularization. Thus, the advantages of this technique could also benefit the results obtained with PCM, providing better vascularization and healing of the periodontal tissues in root coverage procedures.

Up to this moment, this is the first study to compare the use of PCM with different surgical techniques. The root coverage obtained after 3 months was superior for the test group (82.33\%) compared with the control group $(60.78 \%)(p<0.01)$. These results were maintained after 6 months (TG: $81.89 \%$; CG: $62.80 \% ; p<0.01)$. Moreover, the test group showed a greater reduction in height and width of the gingival recessions when compared to the control group at 3 and 6 months (Table 2). One possible explanation is 
the fact that the EFT used in the test group can promote better vascularization in the center of the flap, due to flap extension, possibly avoiding its contraction in the healing period. In this study, the test group showed greater root coverage compared to the control group, but the test group showed a lower rate of root coverage when compared to other studies $(6,9)$. Still, the present study presented better results for root coverage than a multicenter study
(5) conducted with PCM. These differences may be due to different samples of the studies. The studies which showed higher root coverage percentages presented smaller gingival recessions (means from $3.09 \mathrm{~mm}$ to $3.14 \mathrm{~mm}$ for test group and from $3.05 \mathrm{~mm}$ to $3.20 \mathrm{~mm}$ for control group) (9), while the multicentric study (5) showed means of $3.34 \mathrm{~mm}$ for the control group and $3.46 \mathrm{~mm}$ for the test group, findings similar to the present study (3.49 for the control group and
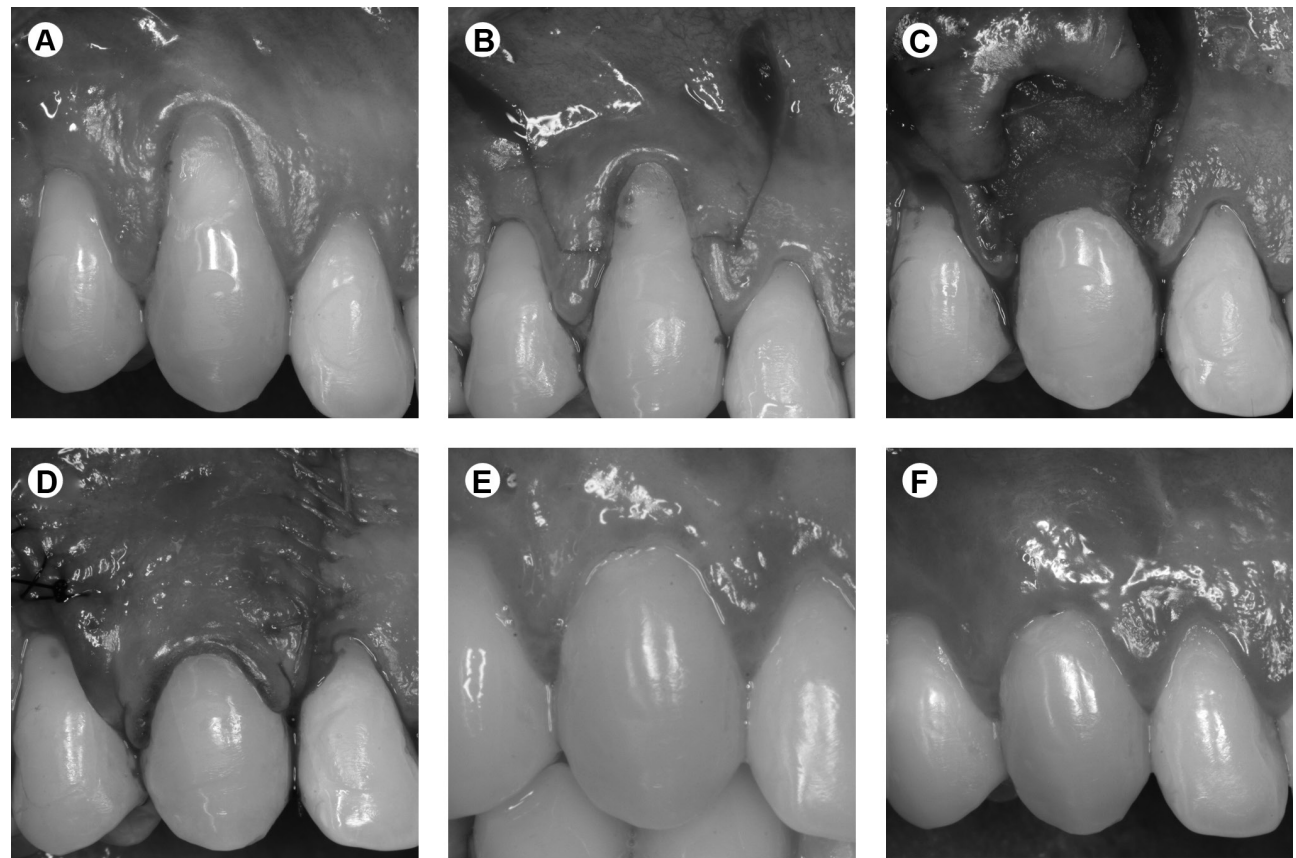

Figure 1. Control group. A: Baseline. B: Incisions. C: PCM sutured. D: Flap sutured. E: Clinical aspect after 3 months. F: Clinical view after 6 months.
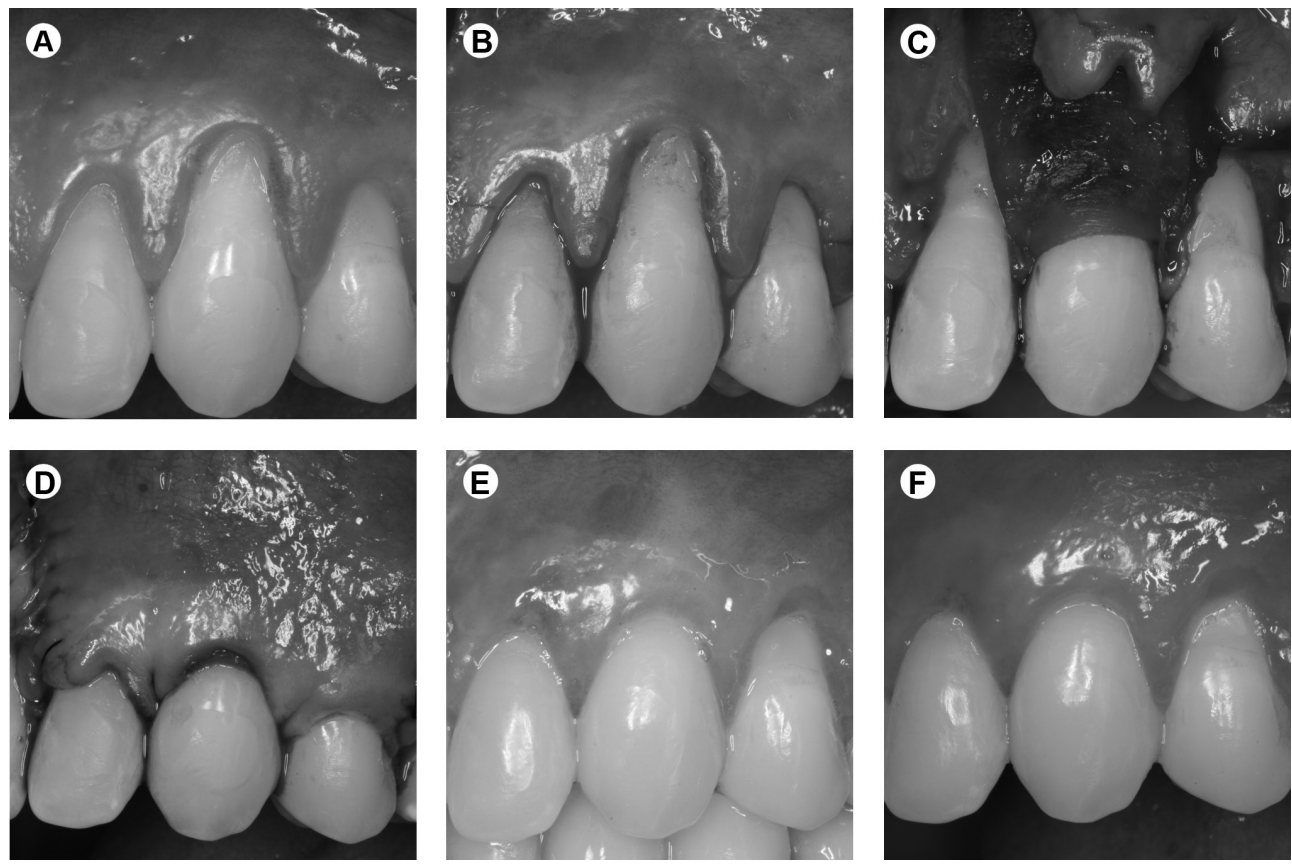

Figure 2. Test Group. A: Baseline. B: Incisions. C: PCM sutured. D: Flap sutured. E: Clinical aspect after 3 months. F: Clinical view after 6 months. 


\subsection{7 for test group).}

For keratinized tissue gain, Cardaropoli et al. (9) obtained after 12 months an increase for the test group from $2.23 \mathrm{~mm}$ to $3.45 \mathrm{~mm}$ when PCM was used. McGuire and Scheyer (6), after 12 months, reported increases from $2.44 \mathrm{~mm}$ to 3.59 $\mathrm{mm}$. Jepsen et al. (5), after 3 months, obtained an increase from $1.97 \mathrm{~mm}$ to $2.59 \mathrm{~mm}$ for the test group and after 6 months, $2.90 \mathrm{~mm}$ in keratinized tissue. The results obtained in the present study showed no difference in the width of keratinized tissue between techniques, and both groups showed lower results than those observed in the literature for keratinized tissue gain. A possible reason may be that the studied sample, for both groups, showed lower values for this parameter at baseline than the baseline values of the other cited studies. The gingival thickness obtained in this study did not vary between surgical techniques after 3 and 6 months of follow up. The measurements were made $1 \mathrm{~mm}$ above and $1 \mathrm{~mm}$ below the mucogingival junction because after surgery the position of the mucogengival junction could change due to the coronal displacement of the flap. In both measurements, the gain of gingival thickness, was lower than the one reported by Cardaropoli et al. (9) ( $0.82 \mathrm{~mm}$ to $1.82 \mathrm{~mm}$ ) and by Jepsen et al. (5) (0.89 $1.37 \mathrm{~mm}$ at 3 months and $1.48 \mathrm{~mm}$ after 6 months). The difference between the results of this study compared to others regarding the increase of gingival thickness may be caused by differences in the clinical measurements or differences in product handling. Another recent study has shown that PCM did not significantly increase gingival thickness (12), corroborating the results of this study.

As reported in the literature $(7,10,13)$, the treatments did not cause clinical attachment loss or change in probing depth. No differences occurred in height or width of the papillae of the neighboring teeth, keeping them undamaged, demonstrating the safety of the test technique as well as good healing when the PCM was applied. The limitations of the study were related to the only that compared the CAF and EFT: a bigger sample and more time of follow up may improve the results and are important for better clinical decisions.

In conclusion, the extended flap technique was able to treat gingival recession, reducing its height and width, with superior results than those obtained using the coronally advanced flap technique.

\section{Resumo}

0 objetivo deste estudo randomizado, controlado e clínico foi comparar para recobrimento radicular a técnica de retalho estendido (EFT) com a técnica de retalho avançado coronalmente (CAF) utilizando uma matriz suína colágena (PCM). Vinte pacientes com duas retrações gengivais bilaterais, classe I ou II de Miller em dentes não molares foram tratados com PCM+CAF (grupo controle) ou PCM+EFT (grupo teste). Medidas clínicas de profundidade de sondagem, (PPD), nível clínico de inserção
(CAL), altura da retração gengival $(\mathrm{RH})$, altura do tecido queratinizado (KTH), espessura da mucosa queratinizada (KMT) foram determinadas no exame inicial, aos 3 e 6 meses após a realização das cirurgias. Após 6 meses a média de recobrimento radicular para o grupo teste foi de $81,89 \%$ e para o grupo controle foi de $62,80 \%(p<0,01)$. A mudança na altura das retrações gengivais em relação ao exame inicial foi estatisticamente significante entre os grupos teste e controle, com média de $2,21 \mathrm{~mm}$ ganhos nos sítios controle e $2,84 \mathrm{~mm}$ ganhos nos sítios teste $(p=0,02)$. Não houve diferenças estatísticas significantes para os parâmetros $\mathrm{KTH}_{\text {, }}$ PPD ou CAL comparando as duas terapias. A técnica de retalho estendido apresentou melhor recobrimento radicular do que a técnica de retalho avançado coronalmente quando a PCM foi usada.

\section{Acknowledgements}

The authors thank The São Paulo State Research Foundation (FAPESP, protocol number 2010/12777-1) and the Brazilian Foundation for the Improvement of Higher Education (CAPES) for the financial support to this study, and Geistlich Brasil for donating the porcine collagen matrix.

\section{References}

1. Chambrone L, Sukekava F, Araujo MG, Pustiglioni FE, Chambrone LA, Lima LA. Root coverage procedures for the treatment of localised recession-type defects. Cochrane Database Syst Rev 2009:CD007161.

2. Cairo $F$, Pagliaro $U$, Nieri M. Treatment of gingival recession with coronally advanced flap procedures: a systematic review. J Clin Periodontol 2008;35:136-162.

3. Sanz M, Lorenzo R, Aranda JJ, Martin C, Orsini M. Clinical evaluation of a new collagen matrix (Mucograft prototype) to enhance the width of keratinized tissue in patients with fixed prosthetic restorations: a randomized prospective clinical trial. J Clin Periodontol. 2009;36:868876.

4. Thoma DS, Jung RE, Schneider D, Cochran DL, Ender A, Jones AA, et al.. Soft tissue volume augmentation by the use of collagen-based matrices: a volumetric analysis. J Clin Periodontol 2010;37:659-666.

5. Jepsen K, Jepsen S, Zucchelli G, Stefanini M, de Sanctis M, Baldini N, et al.. Treatment of gingival recession defects with a coronally advanced flap and a xenogeneic collagen matrix: a multicenter randomized clinical trial. J Clin Periodontol 2013;40:82-89.

6. McGuire MK, Scheyer ET. Xenogeneic collagen matrix with coronally advanced flap compared to connective tissue with coronally advanced flap for the treatment of dehiscence-type recession defects. J Periodontol 2010;81:1108-1117

7. Sanctis M, Zucchelli G. Coronally advanced flap: a modified surgical approach for isolated recession-type defects: three-year results. J Clin Periodontol 2007;34:262-268.

8. Barros RR, Novaes AB, Grisi MF, Souza SL, Taba MJ, Palioto DB. A 6-month comparative clinical study of a conventional and a new surgical approach for root coverage with acellular dermal matrix. J Periodontol 2004;75:1350-6.

9. Cardaropoli D, Tamagnone L, Roffredo A, Gaveglio L. Treatment of gingival recession defects using coronally advanced flap with a porcine collagen matrix compared to coronally advanced flap with connective tissue graft: a randomized controlled clinical trial. J Periodontol 2012;83:321-328.

10. Miller PD, Jr. A classification of marginal tissue recession. Int J Periodontics Restorative Dent 1985;5:8-13.

11. Oates TW, Robinson M, Gunsolley JC. Surgical therapies for the treatment of gingival recession. A systematic review. Ann Periodontol 2003;8:303-320.

12. Thoma DS, Hammerle $\mathrm{CH}$, Cochran DL, Jones AA, Gorlach C, Uebersax $L$, et al.. Soft tissue volume augmentation by the use of collagen-based matrices in the dog mandible: a histological analysis. J Clin Periodontol 2011;38:1063-1070. 